\title{
Phenotypic variation in the coral Platygyra daedalea in Kenya: morphometry and genetics
}

\author{
Sangeeta Mangubhai ${ }^{1}$, Petra Souter ${ }^{2,3, *}$, Mats Grahn ${ }^{2}$ \\ ${ }^{1}$ School of Environmental Science \& Management, Southern Cross University, Lismore, New South Wales 2480, Australia \\ ${ }^{2}$ Molecular Ecology Group, School of Life Sciences, Södertörn University College, 14189 Huddinge, Sweden \\ ${ }^{3}$ Present address: Australian Institute of Marine Science, PMB No 3, Townsville MC, Queensland 4810, Australia
}

\begin{abstract}
High intraspecific variability and lack of adequate field descriptions or distinguishing skeletal features has made identification of the scleractinian coral Platygyra daedalea challenging. This species displays a number of distinct morphological types that co-occur on lagoonal reefs in Kenya and which often cannot be separated by field observations. To better understand how morphological and genetic variations are related, morphometric and molecular techniques were used to examine phenotypic variation in P. daedalea. A canonical discriminant analysis of measurements of 10 skeletal characters confirmed the existence of 2 morphotypes. No single diagnostic trait could be used to distinguish the 2 morphotypes, though a combination of 4 characters separated them. A mathematical equation is presented to separate colonies into the 2 morphotypes, where field identification is not possible. Genetic differentiation was studied using 5 microsatellite loci and sequence analysis of the internal transcriber spacer (ITS1 and ITS2) and 5.8S region of the nuclear ribosomal RNA gene. AMOVA of the microsatellite and ITS sequence data showed significant genetic differences between the 2 morphotypes. However, phylogenetic analysis of the ITS sequences showed no evidence of sequence divergence between morphotypes, which suggests that they share a gene pool, or that the genetic divergence is recent. We conclude that the occurrence of distinct morphotypes is a characteristic of $P$. daedalea and that there does appear to be a genetic basis for separating morphotypes. However, genetic differences in $P$. daedalea could only be detected when combined with morphometric data.
\end{abstract}

KEY WORDS: Coral reefs · Taxonomy $\cdot$ Morphotypes $\cdot$ Indian Ocean $\cdot$ Platygyra daedalea

\section{INTRODUCTION}

Traditionally, the species unit has formed the basis for understanding ecology, evolutionary biology and biogeography. However, over recent decades increasing inclusion of novel molecular techniques in phylogeny has led to several cases where current classifications have been brought into question. Well-established species with clear differences in morphology and ecology may be almost indistinguishable at a genetic level. For example, the Old World buzzard group (birds of prey, genus Buteo) includes a plethora of species and subspecies based on variable characters such as plumage colour and body size, but almost no sequence variability was found in the pseudo-control region of mitochondrial DNA (Kruckenhauser et al. 2003). In contrast, there are cases where conservative morphological taxonomy has underestimated species diversity, as in the deep-sea mussel Acharax sp., which was thought to be a single species until molecular studies allowed separation into 2 distinct genetic clusters (Neulinger et al. 2006). In scleractinian corals, the high degree of intraspecific phenotypic variability makes taxonomic resolution of species in the field subjective (Veron 2000). Corals show morphological plasticity in response to habitat and environment variables (Foster 1979, Lang 1984). Field identification is further confounded by the potential for some species of coral to cross-fertilize (Willis et al. 1997) and form viable hybrids with distinct morphologies (Vollmer \& Palumbi 
2002), or to form distinct morphological types ('morphotypes') within a species (Miller 1994).

Scleractinian coral taxonomy has been based on macroscopic and microscopic skeletal morphology (Vaughan \& Wells 1943, Veron et al. 1977, Wallace 1999) on the premise that morphological discontinuities determine species divisions. While morphometric approaches have been successful in distinguishing many coral genera and species (e.g. Wallace 1974, Veron \& Wallace 1984), difficulties have arisen in their applicability to taxa such as those of the Family Faviidae, where many of the skeletal characteristics overlap between different species from similar or different habitats (Wijsman-Best 1974, Veron et al. 1977, Veron 2000). Genetic studies in some cases have supported original classifications based on morphology (Ayre et al. 1991, Mate 2003), while in others they have led to the separation of intraspecific morphological groups into distinct species (Stobart \& Benzie 1994, Stobart 2000). Hence, the integration of morphometric and molecular studies has not consistently demonstrated whether morphological species of corals should be separated or amalgamated.

High intraspecific variation occurs in Platygyra spp. on the Great Barrier Reef (GBR), Australia (Miller 1994). Seven morphotypes described by Miller (1994) did not correspond to any particular habitat type (Miller 1992, 1994). Platygyra daedalea displayed 4 distinct morphotypes on the GBR, and the skeletal characters of $P$. daedalea and $P$. sinensis differed consistently and significantly. Allozyme electrophoretic surveys of $P$. daedalea, $P$. sinensis and $P$. pini at 9 loci showed no relationship between genotype and morphological groupings at the species or intraspecies level, suggesting morphological species of Platygyra share a common gene pool (Miller 1992, Miller \& Benzie 1997). In contrast, a study in Hong Kong on $P$. pini and 4 morphotypes of $P$. sinensis found genetic differences between the 2 species using ITS1, 5.8S and partial ITS2 rRNA sequence analysis, but not between morphotypes, with no diagnostic characters or clear groupings in morphological traits (Lam \& Morton 2003). These conflicting results suggest that the use of more variable or rapidly evolving molecular markers may be more appropriate for distinguishing between similar species, and even more so when comparing 2 morphotypes of the same species. The disparities may also simply reflect the difficulties associated with field identification of these species.

Of the 8 species of Platygyra that have been recorded in Kenya, $P$. daedalea is dominant in lagoonal and fringing reefs, with a wide distribution along the coast (D. Obura unpubl. data). It is an important species in Kenya, particularly since it has shown a certain level of resistance to mass bleaching events, such as those in the western Indian Ocean during the 1997 to 1998 El-Niño Southern Oscillation (Obura 2001). Colonies within the Mombasa lagoon are massive, often hemispherical in form and show a variety of characters that are recognisable in the field. At the colony level, there is consistency in growth form, but at the corallite-level, colonies vary considerably in outward appearance, for example in septa shape, wall height, wall slope and the length and width of valleys (S. Mangubhai pers. obs.).

Detailed skeletal or molecular studies on corals are time-consuming, costly and not practical for routine ecological studies. Most researchers rely heavily on field guides, so it is important to define the variety of physical features a species such as Platygyra daedalea displays in different localities to investigate whether specific morphotypes do exist, their potential ecological role, and to determine whether there is a genetic basis for separating them. Where intermediate forms exist, quantitative methods are needed that are less subjective than univariate approaches and can distinguish colonies into specific morphotypes (Miller 1994). The purpose of our study was to (1) identify intraspecific morphological variation in $P$. daedalea, expressed in both the field observable traits and skeletal morphology, and to determine its relationship with genotypic traits, (2) develop a methodology for distinguishing different forms of $P$. daedalea into specific morphotypes, and (3) assess the level of molecular distinction between morphotypes using microsatellite markers and sequence variation at 2 ITS regions of the rRNA gene. By examining relationships between field and skeletal morphologies and genetic traits, we can start to understand intraspecific variation and taxonomic boundaries in $P$. daedalea and hence reduce the possibility of taxonomic error (Miller 1992, 1994).

\section{MATERIALS AND METHODS}

Field identification. Adult colonies of Platygyra daedalea were identified in the field in accordance with Veron et al. (1977) and Veron (2000) at 3 patch reefs in the Mombasa Marine National Park and Reserve, Kenya between 2003 and 2005 (Fig. 1). Kijembe and Nyali Reefs are separated by about $250 \mathrm{~m}$, and Coral Gardens is situated approximately $7 \mathrm{~km}$ north of Nyali Reef. All 3 sites were in the lagoon at 0.5 to $1.5 \mathrm{~m}$ mean low water depth and experienced similar temperature and tidal regimes (S. Mangubhai unpubl. data). Patch reefs within the Mombasa lagoon are fairly uniform, and the benthic cover and coral community structure and composition were similar at the 3 sites (S. Mangubhai, unpubl. data). Thirty-nine corals were selected at Coral Gardens $\left(3^{\circ} 59^{\prime} 26^{\prime \prime} \mathrm{S}\right.$, 


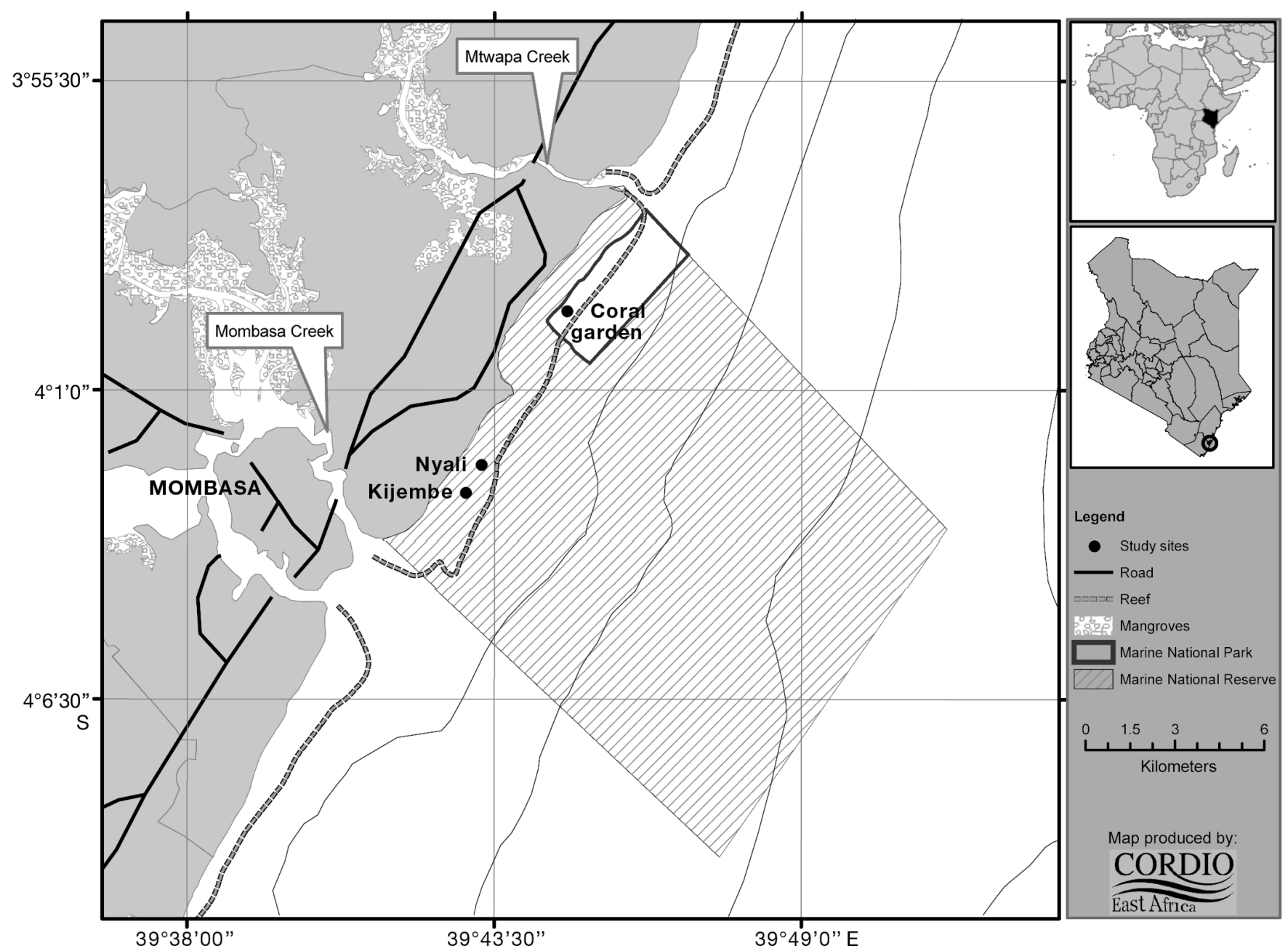

Fig. 1. Platygyra daedalea. Study sites in the Mombasa Marine National Park and Reserve in Kenya

$\left.39^{\circ} 45^{\prime} 1^{\prime \prime} \mathrm{E}\right), 48$ at Nyali Reef $\left(4^{\circ} 3^{\prime} 44^{\prime \prime} \mathrm{S}, 39^{\circ} 42^{\prime} 44^{\prime \prime} \mathrm{E}\right)$ and 46 at Kijembe Reef $\left(4^{\circ} 3^{\prime} 37^{\prime \prime} \mathrm{S}, 39^{\circ} 42^{\prime} 44^{\prime \prime} \mathrm{E}\right)$ with the aim of including the full range of phenotypic traits or 'morphological varieties' observed in the lagoon.

Only 4 characters, viz. wall height, septa slope, septa shape and the prominence of the wall relative to the valley were useful in distinguishing corals into groups recognisable in the field, and on this basis 2 distinct morphotypes were identified a priori: (1) prominent valley (PDV), i.e. colonies with septa of mixed sizes and spacing, with short to medium walls that slope, and valleys that are more prominent (and appear wider) than the walls (Fig. 2a,b); while colour is not a useful distinguishing trait, in many instances this morphotype has brown walls and green valleys; (2) straight-walled (PDSW) i.e. colonies have septa of equal size and even spacing, with tall and straight walls, such that the walls are more prominent (and partially hide) the valleys; growth form is more consistent in this morphotype, is mostly hemispherical, and in most instances wall and valley colours are similar (beige/cream), with a distinctive ridge forming at the top of the wall (Fig. 2c,d).

Many corals had field characteristics that were a mixture of PDV and PDSW morphotypes, and these were classified as 'intermediate forms' and subdivided into 3 smaller groups: E with uneven septa, wall either short or medium in height, walls and valleys equally prominent; F with even septa, walls straight and medium height, wall equal or more prominent than valley; and $\mathrm{H}$ including the remaining corals with a mix of many characters that did not allow assignment into larger groupings. Of the 133 colonies sampled, 27 were identified in the field and by photographs as PDV, 18 as PDSW, and 88 as intermediate forms.

Skeletal characters. Samples for morphometric analysis of the skeletons were approximately $10 \times 10 \mathrm{~cm}$. They were removed from colonies using a hammer and chisel. We avoided injured areas and the growing edge of the colonies, which can have atypical skeletal char- 


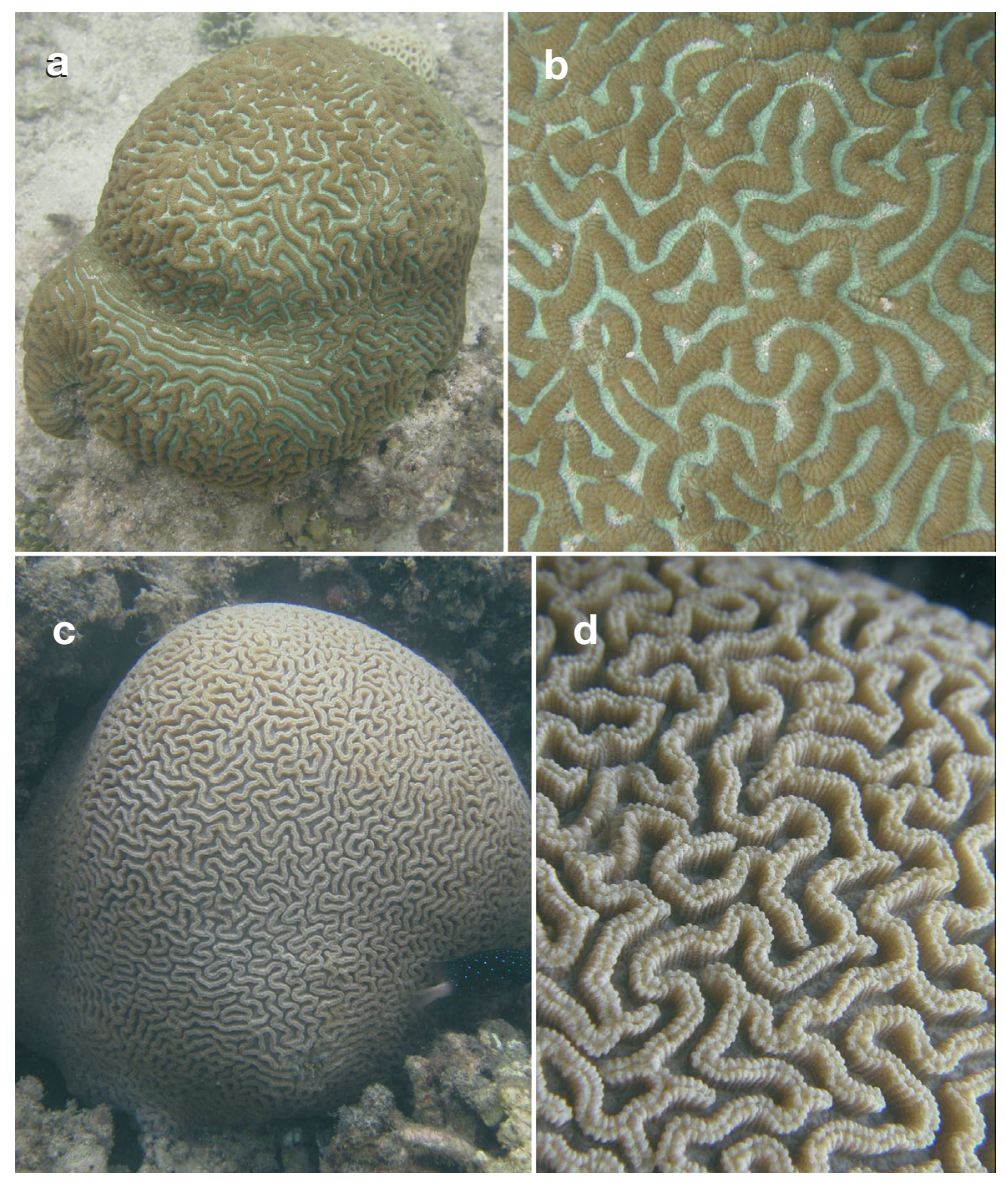

Fig. 2. Platygyra daedalea. Morphotypes found in Kenyan lagoonal reefs. $(\mathrm{a}, \mathrm{b})$ Prominent valley (PDV, max. colony diameter $49 \mathrm{~cm})$; $(\mathrm{c}, \mathrm{d})$ straightwalled form (PDSW, max. colony diameter $75 \mathrm{~cm}$ ) metric analyses to distinguish these morphotypes. We used t-tests to examine differences between PDV and PDSW for each of the 10 characters, and all $\mathrm{p}$ values $<0.05$ were considered significant. A canonical discriminant analysis (CDA) was performed on the 10 skeletal characters to determine whether they separated the 2 morphotypes, and if so, which best discriminated between the 2. All characters were normally distributed except for PA, which had slightly skewed data ( $p<0.01$, Kolmogorov-Smirnov test). Given that CDA is robust to deviations from normality, PA was included the analysis. The CDA generated a function to produce discriminant scores, which was then used to predict how closely related the remaining intermediate forms were to PDV or PDSW. All analyses were done in SPSS 11.0 for Windows.

Genetics. A total of 69 colonies of Platygyra daedalea were selected in May 2005 for genetic analyses. At the time of collection, morphometric analyses of the skeletons had not been completed and colonies were identified in the field as 25 PDV, 5 PDSW and 39 intermediate forms. Following morphometric analyses, genetic samples were correctly labelled and analysed as follows: 59 PDV (Coral Gardens $\mathrm{n}=21$, Nyali Reef $n=20$, Kijembe Reef $n=18$ ) and 10 PDSW (Coral Gardens $\mathrm{n}=4$, Nyali Reef acters (Miller 1994). Nine skeletal characters defined by Miller (1994) were selected for this study, viz. valley length (VL), valley width (VW), valley depth (VD), columella width (CW), septa thickness (ST), theca thickness (TT), exertness of septa (ES), polyp area (PA), and number of septa per cm length (SCM). A tenth character, wall width (WW), defined as the length of individual septa that formed the width of a wall, was also added (Fig. 3). Numerical values were averaged across a minimum of 5 (and where time permitted, 10) measurements taken randomly on the skeletal piece under a stereomicroscope with a calibrated eyepiece micrometer. Valley length and polyp area were measured from photographs of the colony (with a scale in the image frame) and in the software program ImageJ 1.32j (available at http://rsb.info.nih.gov/ij/download. html).

All analyses were performed on the mean values of the skeletal characters measured on each colony. Only colonies that were clearly identified in the field as PDV ( $\mathrm{n}=27)$ or PDSW $(\mathrm{n}=18)$ were included in morpho-

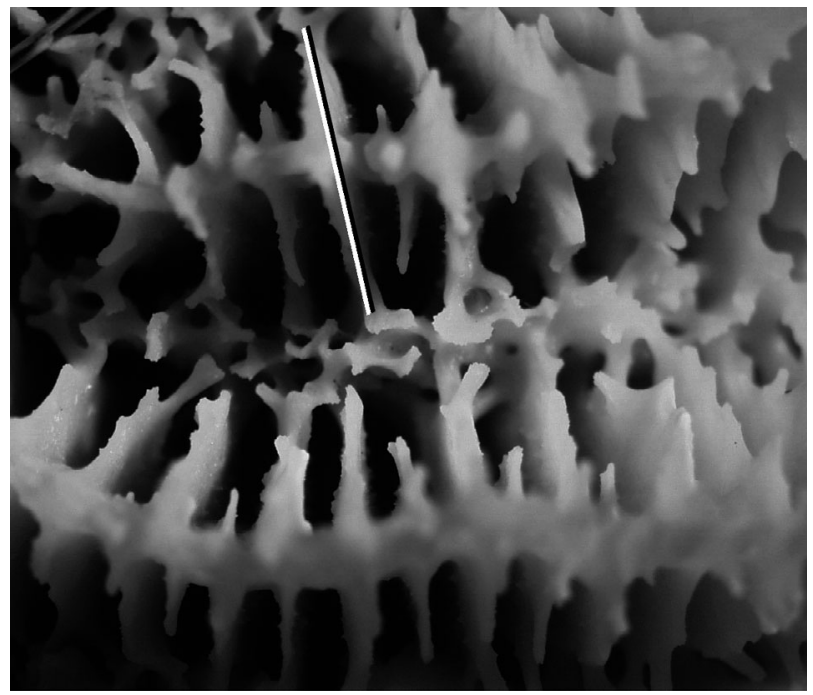

Fig. 3. Platygyra daedalea. Skeleton: line (scale: $4 \mathrm{~mm}$ ) indicates how wall width was measured. See Fig. 1 in Miller (1994) for diagrammatic representation of remaining 9 skeletal characters used in this study 
$\mathrm{n}=6$ ). Small pieces, approximately $1 \mathrm{~cm}^{2}$, were removed from the 69 colonies using a hammer and chisel and placed in separate labelled Ziploc ${ }^{\circledR}$ bags. The samples were subsequently transferred into $10 \mathrm{ml}$ centrifuge tubes filled with $70 \%$ ethanol and kept at ambient temperature until transported back to the laboratory.

DNA was extracted using the Qiagen ${ }^{\circledR}$ DNEasy kit according to the protocol for rodent tails. Fragments were placed directly into lysis buffer and kept in a water bath at $50^{\circ} \mathrm{C}$ overnight. We amplified a fragment of nuclear ribosomal DNA (rRNA) that has been used in a number of genetic studies of scleractinian corals (Takabayashi et al. 1998, Lam \& Morton 2003) using the coral-specific forward primer A18S (Takabayashi et al. 1998) (GenBank accession number X53498) and the universal reverse primer ITS4. The Polymerase Chain Reaction (PCR) was carried out in a $20 \mu \mathrm{l}$ reaction using $100 \mathrm{ng}$ DNA, $0.75 \mathrm{U}$ AmpliTaq, $0.5 \mu \mathrm{l}$ of each primer (conc. $10 \mathrm{ng} \mathrm{hl}^{-1}$ ) and a concentration of $0.5 \mathrm{mM}$ of each dNTP, and $0.15 \mathrm{mM}$ of $\mathrm{MgCl}_{2}$. PCR products were purified and sequenced by Macrogen Inc., using the same primers that had been used for the PCR reaction.

Given that microsatellite loci are more polymorphic and evolve more rapidly than other DNAs such as rDNA (Baker 2000), they may show a higher degree of divergence between morphotypes or potentially unique alleles, provided there is some reproductive barrier in place. For this study we used 5 fluorescently labelled microsatellite primers developed for Platygyra species (Miller \& Howard 2004). The PCR was carried out in a $10 \mu \mathrm{l}$ reaction using $25 \mathrm{ng}$ of DNA, $0.5 \mathrm{U}$ AmpliTaq, $0.25 \mathrm{mM}$ of each dNTP, and $0.5 \mathrm{mM}$ of each primer. Cycling protocol was initiated with $5 \mathrm{~min}$ at $94^{\circ} \mathrm{C}$ followed by 30 cycles of $94^{\circ} \mathrm{C}$ for $30 \mathrm{~s}, 54$ to $60^{\circ} \mathrm{C}$ (locus Pd29 at $54^{\circ} \mathrm{C}, \operatorname{Pd} 31$ at $56^{\circ} \mathrm{C}, \operatorname{Pd} 48$ at $60^{\circ} \mathrm{C}$, Pd61 at $58^{\circ} \mathrm{C}$, Pd62 at $57^{\circ} \mathrm{C}$ ) for $30 \mathrm{~s}$, and $72^{\circ} \mathrm{C}$ for $1 \mathrm{~min}$, and finalised with an extra extension period at $72^{\circ} \mathrm{C}$ for 10 min. PCR products, as well as positive and negative controls, were genotyped on an ABI 3700 capillary sequencer (Applied Biosystems) using a Gene Scan-500 Rox size standard provided by ABI, and visualised using GeneMapper v. 3.7 (Applied Biosystems). One microsatellite locus, Pd29, was found to be monomorphic and was subsequently excluded from analysis.

The ITS rRNA sequences were aligned manually using BioEdit v. 7.0 (Hall 1999) and exported to MEGA v. 3.1 (Kumar et al. 2004), which was used to reconstruct a phylogeny of the individuals based on the Maximum Parsimony optimality criterion with heuristic search. To align our genetic samples with a previous study of Platygyra species from Hong Kong, we included sequences of each morphotype of $P$. sinensis (GenBank accession numbers AF481885, AF481888, AF481895) and P. pini from the same subfamily (Gen-
Bank accession number AF481902) (Lam \& Morton 2003). Montastrea franksi, which belongs to the same family but different subfamily (GenBank accession number AB065349) was used as an outgroup. Branch support levels were estimated using 1000 bootstraps. Sequence divergence was estimated using Kimura's 2-parameter model (Kimura 1980).

To examine genetic differences between the 2 morphotypes both within each site and after pooling the sites, and to assess the difference between the study sites with morphotypes pooled, an Analysis of Molecular Variance (AMOVA) was done using the programme Arlequin (Laval \& Schneider 2005) with both ITS and microsatellite data. The genetic distance method used by the AMOVA was pair-wise population subdivision $\left(\mathrm{F}_{\mathrm{ST}}\right)$, which was estimated according to Cockerham \& Weir (1984). The significance values were calculated using 20000 non-parametric permutations. This procedure is appropriate when dealing with unbalanced sample sizes, as it does not assume normality or equality of variances among samples.

As PDV was found to be phenotypically more variable, we investigated whether this variability was reflected at the molecular level by assessing average molecular diversity over loci for each morphotype (using Arlequin), in accordance with Tajima (1983, 1993). Hardy-Weinberg equilibrium tests were performed to gauge population structures, and assignment tests were conducted on the log-likelihood of individual genotypes being classified correctly as PDV or PDSW, as predicted by the CDA. The significance values for the Hardy-Weinberg tests and $\mathrm{F}_{\mathrm{ST}}$ values were calculated using permutation tests (Laval \& Schneider 2005).

The programme Structure v. 2.0 (Pritchard et al. 2000) was used to examine possible subpopulations by assigning individuals to clusters according to their 4 -loci microsatellite genotypes. The underlying hypothesis was that the sampled individuals should cluster into the 2 morphotypes, or alternatively into the 3 sample sites. A series of analyses at a range of K-values $(1-4)$ was done to ascertain the most probable number of clusters. A burn-in of 25000, and a 250000 run length were used.

\section{RESULTS}

\section{Morphometrics}

A comparison of mean values and their ranges for PDV and PDSW for each of the 10 skeletal characters found that there was no single diagnostic character suitable for separating the morphotypes (Table 1). There were significant differences between the 2 
Table 1. Platygyra daedalea. Mean values of 10 skeletal characters for all colonies and for morphotypes PDV and PDSW. p values generated by F-statistics apply to comparisons of morphotypes PDV and PDSW. All measurements in mm, except polyp area in cm ${ }^{2}$

\begin{tabular}{|c|c|c|c|c|c|}
\hline Character & Code & P. daedalea & PDV & PDSW & $\mathrm{p}$ \\
\hline No. of septa $\mathrm{cm}^{-1}$ length & $\mathrm{SCM}$ & $12.9(8.8-15.7)$ & $13.4(11.0-14.9)$ & $11.2(8.8-13.4)$ & $<0.001$ \\
\hline Wall width & WW & $4.0(2.9-5.1)$ & $3.7(3.2-4.3)$ & $4.4(3.8-5.1)$ & $<0.001$ \\
\hline Polyp area & $\mathrm{PA}$ & $11.4(6.4-28.7)$ & $9.7(6.6-12.3)$ & $15.4(10.4-28.7)$ & $<0.001$ \\
\hline Valley depth & VD & $4.3(2.7-7.2)$ & $4.0(3.0-6.4)$ & $5.2(3.4-7.2)$ & $<0.001$ \\
\hline Valley width & VW & $5.6(3.9-7.2)$ & $5.4(4.1-7.1)$ & $6.2(5.5-7.2)$ & $<0.001$ \\
\hline Valley length & VL & $5.9(1.4-12.1)$ & $5.5(1.6-11.6)$ & $7.3(2.2-11.8)$ & 0.018 \\
\hline Corallum width & CW & $1.1(0.8-1.5)$ & $1.1(0.8-1.4)$ & $1.1(0.9-1.4)$ & 0.055 \\
\hline Septa thickness & $\mathrm{ST}$ & $0.2(0.1-0.4)$ & $0.2(0.1-0.2)$ & $0.2(0.1-0.4)$ & 0.097 \\
\hline Theca thickness & TT & $0.9(0.5-1.7)$ & $0.9(0.6-1.3)$ & $0.1(0.5-1.2)$ & 0.134 \\
\hline Exertness of septa & ES & $1.0(0.3-2.4)$ & $1.0(0.4-2.0)$ & $0.8(0.3-1.5)$ & 0.162 \\
\hline Number of colonies & & 133 & 27 & 18 & \\
\hline
\end{tabular}

morphotypes for 6 of 10 characters (PA, SCM, VD, VW, WW and VL, Table 1).

A stepwise CDA identified the 4 skeletal variables SCM, WW, PA and ST as the best set of predictors of membership in the 2 groupings PDV and PDSW. One discriminant function was produced with an eigenvalue of 1.806 , which accounted for $100 \%$ of the variance among the 4 variables. Discriminant scores for the function were highly correlated with the groupings $\left(\mathrm{r}^{2}=0.64\right)$. Standardised coefficients showed all 4 characters contributed to the discriminant function in roughly equal proportions, with SCM being inversely related to the other 3 characters (Table 2).

A pooled within-groups covariance matrix classification procedure for the 2 morphotypes was done, where membership in groups was based on prior probabilities that took into account different group sizes. The classification procedure showed that $26(96.3 \%)$ colonies of

Table 2. Platygyra daedalea. The unstandardised and standardised discriminant function coefficients generated by the CDA for morphotypes PDV and PDSW colonies. See Table 1 for character codes

\begin{tabular}{|lrc|}
\hline Characters & Unstandardised & Standardised \\
\hline WW & 1.678 & 0.578 \\
ST & 10.090 & 0.424 \\
PA & 0.122 & 0.423 \\
SCM & -0.319 & -0.361 \\
Constant & -5.903 & \\
\hline
\end{tabular}

Table 3. Platygyra daedalea. The percentages of corals correctly and incorrectly classified into the 2 morphotypes PDV and PDSW by the canonical discriminant analysis. Numbers of corals in parentheses

\begin{tabular}{|lcccc|}
\hline Classification & Morphotype & Correct & Incorrect & Overall success (\%) \\
\hline Original & PDV & $96.3(26)$ & $3.7(1)$ & $91.1(45)$ \\
& PDSW & $83.3(15)$ & $6.7(3)$ & \\
Cross-validated & PDV & $96.3(26)$ & $3.7(1)$ & $88.9(45)$ \\
& PDSW & $77.8(14)$ & $22.2(4)$ & \\
\hline
\end{tabular}

PDV and 15 colonies of PDSW (83.3\%) were correctly identified (Table 3). Overall, 41 of the 45 of colonies $(91.1 \%)$ were correctly identified. Cross-validation (where each colony in the analysis is classified by the functions derived from all colonies other than that colony) was also performed to test whether the original classification procedure provided overly-optimistic estimates of group membership. The test showed there was little difference between the original and crossvalidation classifications (i.e. only one coral changed its grouping), and therefore the original classification scheme was robust and the number of variables used in the model was correct (Table 3).

A discriminant function coefficient matrix was produced from the CDA solution on the 4 diagnostic variables (Table 2), and the unstandardised coefficient values were used to calculate the discriminant score (DS) for each intermediate form colony using the equation below:

$$
\begin{aligned}
\mathrm{DS}=- & 5.903+(\mathrm{WW} \times 1.678)+(\mathrm{ST} \times 10.09)+ \\
& (\mathrm{PA} \times 0.122)-(\mathrm{SCM} \times 0.319)
\end{aligned}
$$

Unstandardised coefficients were selected to enable application of the function to new data using raw variables. A bi-plot of the discriminant scores for PDV, PDSW and intermediate forms was produced (Fig. 4). The 4 incorrectly grouped colonies (identified by classification procedure) were responsible for observable overlap between morphotypes. Once colonies were reassigned to the group designated by the classification procedure, it was clear that all negative discriminant scores corresponded to PDV, and all positive scores corresponded to PDSW, and there was no large gap between the 2 morphotypes' scores (Fig. 4).

Discriminant scores calculated for each intermediate form showed $78.4 \%$ of colonies to be PDV and $21.6 \%$ to be PDSW (Table 4). Almost all form E 


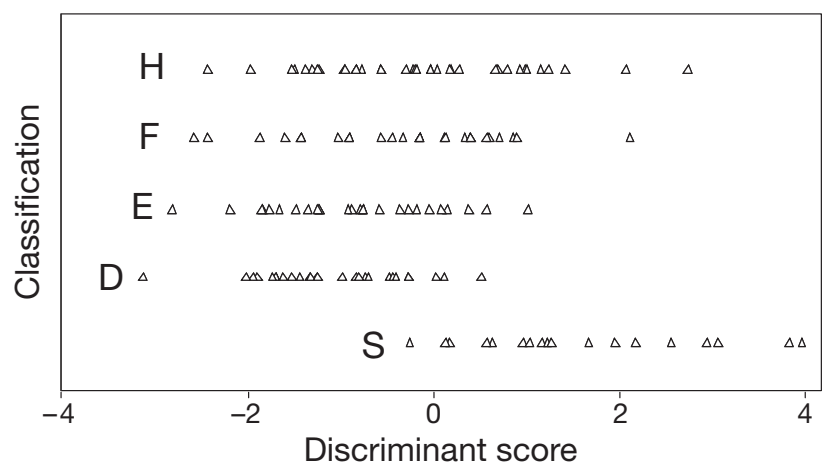

Fig. 4. Platygyra daedalea. Groupings by discriminant scores. S: PDSW; D: PDV; E, F, H: intermediate forms

colonies belonged to PDV (92.3\%) and only 2 colonies were misidentified in the field. By contrast, colonies belonging to forms $\mathrm{F}$ and $\mathrm{H}$ were more difficult to classify into the 2 morphotypes with accuracy, based on field identifications alone (Table 4). The inclusion of form E within PDV means that the field description for PDV should read 'colonies have septa of mixed sizes and spacing, with short to medium walls that slope, and valleys that are more prominent (and appear wider) or are equal to the walls'. These results show PDV to be the dominant morphotype in Kenyan lagoonal reefs, with $73.7 \%$ of all corals in this study belonging to this group.

\section{ITS sequencing}

The rRNA fragment was successfully sequenced to include the ITS1, 5.8S and the complete ITS2 region in 52 individuals, of which 10 were classified as PDSW and 42 as PDV by the CDA. Sequences of the remaining 17 individuals (16 PDV and 1 PDSW) were poor or incomplete and were excluded from further analysis. No specific morphotype or sample site was dominant among the excluded genetic samples.

The sequence aligned 639 positions of which 72 were variable and 29 were potentially parsimony informative. Cloning was not performed as we found no

Table 4. Platygyra daedalea. Percentages of intermediate forms $(E, F, H)$ classified into 2 morphotypes. Numbers of corals indicated in parentheses

\begin{tabular}{|lcc|}
\hline Group & PDV & PDSW \\
\hline E & $92.3(24)$ & $7.7(2)$ \\
F & $76.9(20)$ & $23.1(6)$ \\
H & $69.4(25)$ & $30.6(11)$ \\
Overall & $78.4(69)$ & $21.6(19)$ \\
\hline
\end{tabular}

evidence of sequence heterogeneity at any of the parsimony informative sites that were used to infer the phylogenetic tree. The complete sequence contained less than $2 \%$ ambiguous sites. The ITS1 region had an average length of 209 bases and varied between 207 and 210. One colony from Kijembe Reef had an additional insertion of 18 bases. The 5.8S gene comprised 168 positions and the ITS2 region varied between 210 and 218 positions. A total of 31 haplotypes were found. There were 9 haplotypes among 10 individuals of PDSW, and 22 haplotypes among 40 individuals of PDV, with no identical haplotypes shared between the 2 morphotypes. Parsimony tests were constructed for the complete rDNA sequence. The average nucleotide substitution per site, measured as Kimura's 2-parameter mean distance, was $0.018 \pm 0.003 \mathrm{SD}$ between PDV and PDSW, and $0.020 \pm 0.005$ between Kenyan samples and the Platygyra sinensis sequences derived from GenBank. No inferred parsimonious tree grouped PDV and PDSW separately, nor did it separate them from sequences of $P$. sinensis (Fig. 5).

Contrary to the phylogenetic analysis, AMOVAs on the sequence data revealed a significant genetic difference between PDV and PDSW, where $22 \%$ of the genetic variation was explained by the difference between the 2 morphotypes when treating all sampling sites as one population $\left(\mathrm{F}_{\mathrm{ST}}=0.20\right.$, $\left.\mathrm{p}=0.017\right)$. There was no genetic structure between populations at the different sites $(p=0.604)$.

\section{Microsatellites}

Microsatellite data revealed a slight difference in genetic diversity measured by expected heterozygosity (Hs) over loci between the 2 morphotypes (PDV $0.26 \pm 0.184 \mathrm{SD}, \mathrm{PDSW} 0.37 \pm 0.24 \mathrm{SD}$ ). Two of 5 loci had significant excesses of heterozygotes in PDV, whereas all loci were in Hardy-Weinberg equilibrium in PDSW. In concordance with the ITS sequence analysis, AMOVAs showed significant subdivisions both between morphotypes within sites $\left(\mathrm{F}_{\mathrm{ST}}=0.055, \mathrm{p}=\right.$ 0.016) and between morphotypes when pooling sampling sites $\left(\mathrm{F}_{\mathrm{ST}}=0.028, \mathrm{p}=0.040\right)$. When doing the AMOVA on each locus separately, it becomes apparent that this difference is caused by a significant differentiation at one locus, $\operatorname{Pd} 48\left(\mathrm{~F}_{\mathrm{ST}}=0.335, \mathrm{p}<0.0001\right)$. None of the other loci showed signs of differentiation. No significant difference was found between sampling sites when pooling morphotypes $\left(\mathrm{F}_{\mathrm{ST}}=-0.041, \mathrm{p}=\right.$ 0.60 ) or between sites within each morphotype (PDSW $\mathrm{F}_{\mathrm{ST}}=-0.15, \mathrm{p}=0.89 ;$ PDV $\mathrm{F}_{\mathrm{ST}}=0.001, \mathrm{p}=0.30$ ).

An assignment test performed using the programme Arlequin on the log-likelihood of individual multiloci genotypes, correctly assigned $87 \%$ of the colonies to 


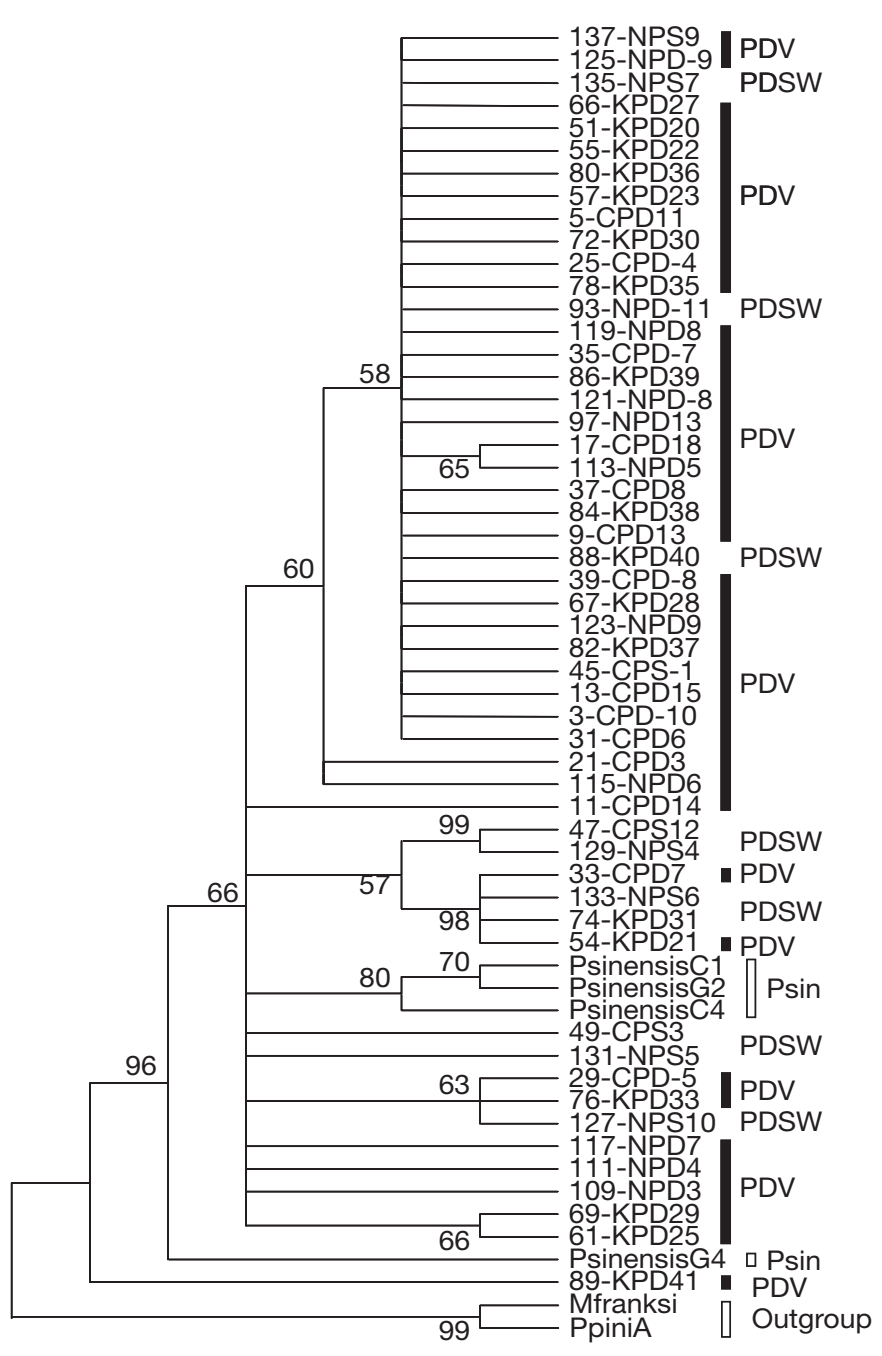

Fig. 5. One of 297 equally parsimonious trees of the complete gene ITS $-1+5.8 \mathrm{~S}+$ ITS -2 constructed using maximum parsimony with 1000 replicates and 1000 bootstraps. Initial tree inferred by random addition. Individual samples are named according to sample site and field identification (CPD/S Coral Gardens PDV/PDSW; NPD/S - Nyali PDV/PDSW; KPD/S - Kijembe PDV/PDSV). Psinensis: Platygyra sinensis; Mfranksi: Montastrea franksi; Ppini: P. pini

the same morphotype designated by the morphometric analysis (94\% of PDV and $63 \%$ of PDSW). Nine individuals were assigned differently to morphotype by the genetic assignment test versus the morphometric analyses. Six of these individuals were originally classified in the field as intermediate forms.

When using only microsatellite genetic data and no prior information on morphotypes, the Bayesian population cluster analysis failed to assign any individuals to specific clusters, and the maximum likelihood values were almost identical for models of $\mathrm{K}=1$ to $\mathrm{K}=4$ (where $\mathrm{K}$ = the inferred number of subpopulations in the data set). The programme Structure was also unable to assign the 39 colonies identified in the field as intermediate forms to either of the 2 morphotypes when using the microsatellite genotypic information of colonies classified in the field as PDC or PDSW. However, after the genetic samples were relabelled following morphometric analysis, we found that the model for $\mathrm{K}=2$ had the highest maximum likelihood and the programme successfully assigned $98 \%$ of PDV and $97 \%$ of PDSW to correct morphotype.

\section{DISCUSSION}

Intraspecific phenotypic variability in scleractinian corals occurs in response to environmental variables (Wijsman-Best 1974, Foster 1980) and genetic differences (Willis \& Ayre 1985), or a combination of both (Foster 1979, Miller 1992). In Kenya, 2 morphotypes of Platygyra daedalea were identified in a single lagoonal habitat type, and these observations were confirmed through morphometric studies. PDV was the dominant morphotype in the lagoon, comprising $73.7 \%$ of the colonies sampled. Skeletal variation was continuous between the 2 morphotypes, and while there was no single diagnostic trait that could be used to distinguish between PDV and PDSW, there were significant differences in 6 of the 10 skeletal characters. These findings contrast with Miller (1994) who found that significant differences could only be detected between morphological species on the GBR when 9 skeletal characters were considered simultaneously.

With the exception of polyp area and valley length, the mean skeletal measurements and their ranges were consistent with those reported for Platygyra daedalea on the GBR (Miller 1994). The narrower range in values in Kenyan colonies most likely reflects the selection of one habitat type for this study, compared to 4 in the GBR study. The overlapping ranges in mean measurements between the different GBR morphotypes means it is not possible to determine whether PDV and PDSW correspond to any of the morphotypes described by Miller (1994) without running a CDA with the data from both regions. Valley length has been used to differentiate between species of Platygyra (Veron et al. 1977, Veron 2000), but was not found to be a useful trait for describing Kenyan colonies, which have valley lengths comparable to P. ryukyuensis and P. pini on the GBR (Miller 1994).

The field descriptions for PDV and PDSW, and the CDA-generated mathematical equation presented in this paper can be used by other researchers in Kenya separately, or in combination, to assign Platygyra daedalea colonies to one of the 2 morphotypes. Measurements of 4 skeletal characters were adequate to distinguish between morphotypes. The CDA classification 
procedure is currently under-utilised by taxonomists, and this study has shown its value in separating taxonomic groups that have overlapping skeletal characters, such as corals belonging to the Family Faviidae.

Phylogenetic analysis of the rRNA ITS sequences revealed no consistent grouping pattern for the 2 morphotypes of Platygyra daedalea in Kenya (Fig. 5). However, both microsatellite and sequence data indicate that there is a small, but significant genetic difference between the 2 morphotypes, though not between study sites, indicating that morphotypes are more genetically separated than sampling sites within the Mombasa Marine National Park and Reserve. In addition, ITS sequence data indicate that these 52 samples of $P$. daedalea are genetically indistinguishable from published sequences from 4 genetic clusters of $P$. sinensis from Hong Kong (Lam \& Morton 2003), raising the issue of the taxonomic status of the $P$. daedalea/ sinensis species complex, or the validity of using ITS sequences to separate species.

An earlier study of the phylogenetic relationships between species of Platygyra used allozymes as genetic markers and found morphological, but no clear genetic differences between species (Miller \& Benzie 1997). As it is often assumed that allozymes are non-neutral markers, and therefore potentially under the influence of stabilising selection, they have relatively low mutation rates (Hartl \& Clark 1997). Also, most mutations that occur in allozyme markers are silent, and as such will not cause a difference in motility on an electrophoretic gel, and hence will be undetected. This will decrease the signals of divergence and increase the chances of not detecting a genotypic difference that may exist.

In contrast, ITS sequencing found genetic distinctions, but no clear morphological clustering was found between Platygyra sinensis and P. pini in Hong Kong (Lam \& Morton 2003). We found morphological differences, but no clear genetic differences using both ITS sequences and microsatellites within the Kenyan corals. The lack of morphological clustering in the Hong Kong study may be attributable to their method of choice for morphometric analysis, which differed from the CDA used by Miller (1994) and our study. Based on these 3 analyses, it appears that the ITS region is sufficiently divergent to be useful at the species level, but may not be variable enough to detect genetic differences between morphotypes with a current or recently shared gene pool.

The ITS sequences presented here are highly diverse, with a large proportion of unique haplotypes, consistent with other studies of corals (van Oppen et al. 2002, Marquez et al. 2003, Fukami et al. 2004). The rate of evolution of nuclear rRNA is believed to allow for differences between species to accumulate through genetic drift, while maintaining similarities between populations within species (Hillis \& Dixon 1991). The use of ITS sequences for phylogenetic and population genetic studies of corals has been questioned based on evidence that corals display a faster rate of speciation than the concerted evolution of the rDNA, resulting in shared ancient rDNA lineages which would obscure processes such as introgressive hybridisation (Vollmer \& Palumbi 2004). However, in the present study the combined results from the analysis of microsatellites and rDNA sequences support the existence of 2 morphotypes of Platygyra daedalea that have evolved and existed in sympatry. While it is not possible to distinguish between these morphotypes using molecular markers alone, in combination with morphological data a significant genetic division is apparent. We used only 4 variable microsatellite loci. Additional variable markers would probably improve the chances of discriminating between the 2 morphotypes based on genetics alone. Individual AMOVA of each microsatellite locus shows that one locus, Pd48, is solely responsible for the inferred differentiation. Hence, it may be speculated that this locus is linked to a gene that is under differential selection in the 2 morphotypes.

It is not clear how morphological boundaries are maintained in Platygyra species or morphotypes, with earlier studies showing there are no apparent gametelevel barriers to fertilisation between species on the GBR (Miller \& Babcock 1997). A recent study in Kenya suggests the timing and duration of gametogenic cycles for PDV and PDSW are similar, with both morphotypes capable of biannual spawning at similar times in August/September and February/March each year (Mangubhai \& Harrison 2007).

In contrast to PDV, PDSW was more genetically diverse (Hs), was in Hardy-Weinberg equilibrium at all microsatellite loci and displayed a far greater proportion of unique haplotypes in the ITS region. PDSW was also more difficult to correctly assign to a morphotype using microsatellite markers. Although it is possible that the prevalence of unique haplotypes is a result of the small PDSW sample size, it may be speculated that these 2 morphotypes share a recent ancestral past and that PDSW is the more ancestral type. Despite being less genetically diverse, PDV is more prevalent and phenotypically diverse, and if it has a selective advantage over PDSW in the sampled environment, it may have evolved assortative mating mechanisms within its morphotype to allow for maintenance of morphological boundaries. However, due to the limited sample size and overall low polymorphism of the microsatellite loci included in the study (Table 5), the genetic data should be interpreted with a degree of caution.

Platygyra morphotypes have now been identified in 3 different locations in the Indo-Pacific Region (Miller 
Table 5. Platygyra daedalea. Allele frequencies for each morphotype (PDV, PDSW)

\begin{tabular}{|lccc|}
\hline Locus & Allele & PDV & PDSW \\
\hline Pd31 & 145 & 0.595 & 0.591 \\
& 155 & 0.388 & 0.409 \\
Pd48 & 160 & 0.017 & 0.000 \\
& 206 & 0.000 & 0.045 \\
& 265 & 0.017 & 0.227 \\
Pd61 & 273 & 0.983 & 0.727 \\
& 198 & 0.000 & 0.091 \\
& 202 & 0.121 & 0.090 \\
Pd62 & 209 & 0.836 & 0.818 \\
& 218 & 0.043 & 0.000 \\
& 190 & 0.009 & 0.045 \\
& 202 & 0.500 & 0.545 \\
& 206 & 0.491 & 0.409 \\
\hline
\end{tabular}

1992, 1994, Lam \& Morton 2003) and the western Indian Ocean (this study). Morphotype differentiation appears to be characteristic of this genus, though it is not known if morphotypes exist in all Platygyra species. We are currently unable to explain why PDV is more prevalent than PDSW in the lagoon and to say whether this prevalence extends to deeper waters of the fringing reef and further along the East African coast. Given the prevalence of morphotypes in this genus, the next logical step would be to determine whether there are ecological differences between morphotypes in P. daedalea. For example, is one morphotype more resilient to bleaching than the other, and does the prevalence of PDV in Kenya reflect differences in responses to bleaching? Therefore, further studies are required to understand the role of different morphotypes, and whether there are costs, benefits and limits to phenotypic plasticity that have ecological and evolutionary consequences.

Acknowledgements. We thank the Kenya Wildlife Service and CORDIO East Africa for proving logistical support, and O. Henriksson who helped with the field collections. Special thanks to K. Miller, D. Obura and P. Harrison for providing advice on the study and reviewing the manuscript, L. Brooks for assisting with statistical analyses and B. Munywoki for providing the map. The comments of 3 anonymous reviewers greatly improved this manuscript. This work was undertaken under Kenyan research permits (MOEST 13/001/32C-15 \& MOEST 13/001/33C-306/5). The genetic work was funded by the Swedish Development Cooperation Agency (Sida) through a PhD grant to P.S. through M.G.

\section{LITERATURE CITED}

Ayre DJ, Veron JEN, Dufty SL (1991) The corals Acropora palifera and Acropora cuneata are genetically and ecologically distinct. Coral Reefs 10:13-18

Baker AJ (2000) Molecular methods in ecology. Blackwell Science Publishers, Toronto
Cockerham CC, Weir BS (1984) Covariances of relatives stemming from a population undergoing mixed self and random mating. Biometrics 40:157-164

Foster AB (1979) Phenotypic plasticity in the reef corals Montastrea annularis (Ellis \& Solander) and Siderastrea siderea (Ellis \& Solander). J Exp Mar Biol Ecol 39:25-54

Foster AB (1980) Environmental variation in skeletal morphology within the Caribbean reef corals Montastrea annularis and Siderastrea siderea. Bull Mar Sci 30:678-709

Fukami H, Budd AF, Levitan DR, Jara J, Kersanach R, Knowlton N (2004) Geographic differences in species boundaries among members of the Montastrea annularis complex based on molecular and morphological markers. Evolution 58:324-337

Hall TA (1999) Bioedit: a user-friendly biological sequence alignment editor and analysis program for Windows 95/98/NT. Nucl Acids Symp Ser 41:95-98

Hartl DL, Clark AG (1997) Principles of population genetics. Sinauer Associates, Sunderland, MA

Hillis DM, Dixon MT (1991) Ribosomal DNA: molecular evolution and phylogenetic inference. Q Rev Biol 66:410-453

Kimura M (1980) A simple method for estimating evolutionary rate of base substitutions through comparative studies of nucleotide sequences. J Mol Evol 16:111-120

Kruckenhauser L, Haring, E, Pinsker W, Reising MJ, Winkler H, Wink M, Gamauf A (2003) Genetic vs. morphological differentiation of Old World buzzards (genus Buteo, Accipitridae). Zool Scripta 33:197-211

Kumar S, Tamura K, Nei M (2004) MEGA 3.1. Integrated software for molecular evolutionary genetics analysis and sequence alignment. Briefings Bioinformatics 5:150-163

Lang JC (1984) Whatever works: the variable importance of skeletal and of non-skeletal characters in scleractinian taxonomy. Palaeont Americana 54:18-44

Lam K, Morton B (2003) Morphological and ITS1, 5.8S, and partial ITS2 ribosomal DNA sequence distinctions between two species Platygyra (Cnidaria: Scleractinia) from Hong Kong. Mar Biotechnol 5:555-567

Laval LG, Schneider S (2005) Arlequin Ver. 3.0: an integrated software package for population genetics data analysis. Evol Bioinformatics Online 1:47-50 (available at: la-press. com/journals.php?pa=toc\&journal_id=17\&folder_id=35)

Mangubhai S, Harrison PL (2007) Gametogenesis, spawning and fecundity of Platygyra daedalea (Scleractinia) on equatorial reefs in Kenya. doi: 10.1007/s00338-007-0297-8

Marquez LM, Miller DJ, MacKenzie JB, van Oppen MJH (2003) Pseudogenes contribute to the extreme diversity of nuclear ribosomal DNA in the hard coral Acropora. Mol Biol Evol 20:1077-1086

Maté JL (2003) Ecological, genetic, and morphological differences among three Pavona (Cnidaria: Anthozia) species from the Pacific coast of Panama. Mar Biol 142:427-440

Miller KJ (1992) Morphological variation in the scleractinian coral Platygyra daedalea (Ellis \& Solander, 1786): genetically or environmentally determined? Proc 7th Int Coral Reef Symp 1:550-556

Miller KJ (1994) Morphological species boundaries in the coral genus Platygyra: environmental influences and taxonomic implications. Mar Ecol Prog Ser 110:19-28

Miller K, Babcock R (1997) Conflicting morphological and reproductive species boundaries in the coral genus Platygyra. Biol Bull 192:98-110

Miller KJ, Benzie JAH (1997) No clear genetic distinction between morphological species within the coral genus Platygyra. Bull Mar Sci 61:907-917

Miller KJ, Howard CG (2004) Isolation of microsatellites from two species of scleractinian coral. Mol Ecol Notes 4:11-13 
Neulinger SC, Sahling H, Süling J, Imhoff JF (2006) Presence of two phylogenetically distinct groups in the deep-sea mussel Acharax (Mollusca: Bivalvia: Solemyidae). Mar Ecol Prog Ser 312:161-168

Obura DO (2001) Can differential bleaching and mortality among coral species offer useful indicators for assessment and management of reefs under stress? Bull Mar Sci 69: 421-442

Pritchard JK, Stephens M, Donnelly P (2000) Inference of population structure from multilocus genotype data. Genetics 155:945-959

Stobart B (2000) A taxonomic reappraisal of Montipora digitata based on genetic and morphometric evidence. Zool Stud 39:179-190

Stobart B, Benzie J (1994) Allozyme electrophoresis demonstrates that the scleractinian coral Montipora digitata is two species. Mar Biol 118:183-190

Tajima F (1983) Evolutionary relationships of RNA-sequences in finite populations. Genetics 105:437-460

Tajima F (1993) Unbiased estimation of evolutionary distance between nucleotide-sequences. Mol Biol Evol 10:677-688

Takabayashi M, Carter D, Ward S, Hoegh-Gulberg O (1998) Inter- and intra-specific variability in the ribosomal DNA sequence in the internal transcribed space region of corals. In: Greenwood JG, Hall NJ (eds) Proc Aust Coral Reef Soc 75th Anniv Conf, Heron Island, October 1997, School of Marine Science, University of Queensland, Brisbane, p 241-248

van Oppen MJH, Willis BL, van Rheede T, Miller DJ (2002) Spawning times, reproductive compatibilities and genetic structuring in the Acropora aspera group: evidence for natural hybridization and semi-permeable species boundaries in corals. Mol Ecol 11:1363-1376

Editorial responsibility: Matthias Seaman (Assistant Editorin-Chief), Oldendorf/Luhe, Germany
Vaughan TW, Wells JW (1943) Revision of the sub-orders, families and genera of the Scleractinia. Geol Soc Am Spec Pap 44:1-363

Veron J (2000) Corals of the world. Australian Institute of Marine Science, Townsville

Veron JEN, Wallace CC (1984) Scleractinia of eastern Australia. Part V. Family Acroporidae, Vol 6. Monogr Ser Aust Inst Mar Sci, Townsville

Veron JEN, Pichon M, Wijsman-Best M (1977) Scleractinia of eastern Australia. Part II. Families Faviidae, Trachyphylliidae, Vol 3. Monogr Ser Aust Inst Mar Sci, Townsville

Vollmer SV, Palumbi, SR (2002) Hybridization and the evolution of reef coral diversity. Science 296:2023-2025

Vollmer SV, Palumbi, SR (2004) Testing the utility of internally transcribed spacer sequences in coral phylogenetics. Mol Ecol 13:2763-2772

Wallace C (1974) A numerical study of a small group of Acropora specimens (Scleractinia: Acroporidae). Mem Qld Mus 17:55-61

Wallace CC (1999) Staghorn corals of the world: a revision of the coral genus Acropora. CSIRO, Collingwood

Wijsman-Best M (1974) Habitat-induced modification of reef corals (Faviidae) and its consequences for taxonomy. Proc 2nd Int Coral Reef Symp 2:217-228

Willis BL, Ayre DJ (1985) Asexual reproduction and genetic determination of growth form in the coral Pavona cactus: biochemical genetic and immunogenic evidence. Oecologia 65:516-525

Willis BL, Babcock RC, Harrison PL, Wallace CC (1997) Experimental hybridization and breeding incompatibilities within the mating systems of mass spawning reef corals. Coral Reefs 16:53-65

Submitted: September 26, 2006; Accepted: April 17, 2007 Proofs received from author(s): August 31, 2007 